\title{
Biological Holism and the Evolution of Ethics
}

\author{
Kristin Shrader-Frechette \\ University of South Florida
}

\section{A review of J. Balrd Callicott's In Defense of the Land Ethic:} Essays in Environmental Phllosophy (Albany: State University of New York Press, 1989)

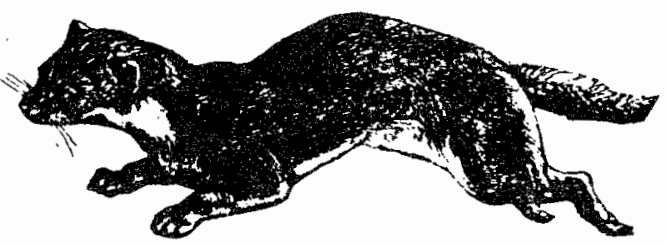

For nearly two decades, J. Baird Callicott has been writing and teaching at the frontier of ethical theory. Perhaps more than almost anyone else, Callicott has been working to extend this frontier in ways that correct the anthropocentric bias of many moral thinkers. Not merely a philosopher who writes about environmental issues, Callicott has been creating a new environmental ethics, one grounded in the thought of Aldo Leopold. His volume, In Defense of the Land Ethic, is an excellent summary of his position. ${ }^{1}$ It is also a good example of his poetic brilliance and his most effective insights.

After highlighting the main contributions of Callicott's book, I shall summarize some of (what I take to be) his best ethical insights. In closing the discussion, I shall suggest several reasons why community ecology and natural selection may not be able to provide support for all of the arguments in which Callicott and others enlist their help.

\section{Callicott's Contributions}

In Chapter One of In Defense of the Land Ethic, ("Animal Liberation: A Triangular Affair"), Callicott argues that the familiar conflict between traditional

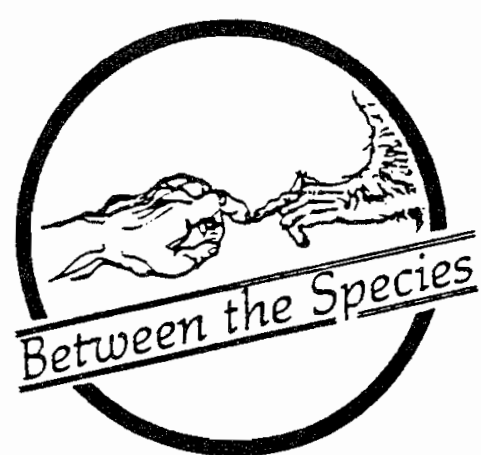

(anthropocentric) moral humanists and the humane moralists (or animal liberationists) ought to be conceived as a triangular, not a polar, debate. He claims that the Leopoldian position of land/environmental ethics represents the third prong of the controversy. The main shortcoming of the two earlier positions, argues Callicott, is that they are atomistic, whereas land/ environment ethics is holistic.

Callicott's holistic environmental ethics "locates ultimate value in the biotic community and assigns differential moral value to the constitutive individuals relatively to that standard." 2 Hence, as he argues in Chapter Two, it makes no sense to attribute rights to individual inanimate objects, because nature "does not respect the rights of individuals." 3 Because trophic processes, for example, do not safeguard rights of individuals, Callicott (in Chapter Three) follows Leopold in providing "only 'respect' for individual members of the biotic community, but 'biotic rights' for species"; further, he says, "in the last analysis, "the integrity, beauty, and stability of the biotic community' is the measure of right and wrong actions affecting the environment." 4

Defending Leopold's (and his) land ethics as Darwinian and sociobiological, in Chapter Five Callicott argues persuasively that the land ethic is a natural result of the evolutionary extension of the boundaries of the moral community. Once we see land
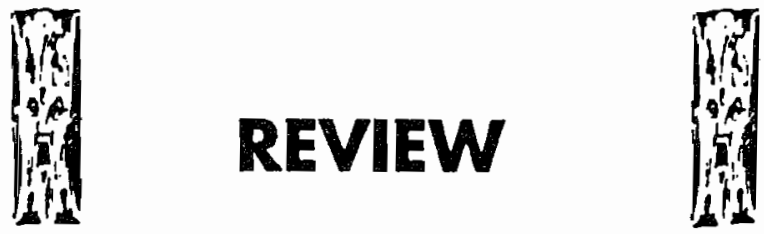
as a "biotic community," says Callicott, the land or environmental ethic emerges. The "conceptual and logical foundations of the land ethic," he says, are evolutionary and ecological biology, "a Copemican cosmology, a Darwinian protosociobiological natural history of ethics, Darwinian ties of kinship among all forms of life on earth, and an Eltonian model of the structure of biocenoses all overlaid on a HumeanSmithian moral psychology. Its logic is that natural selection has endowed human beings with an affective moral response to perceived bonds of kinship and community membership and identity; that today the natural environment, the land, is represented as a community." 5 More specifically, Callicott argues that the biotic community, currently viewed as the ecosystem, has moral considerability because it is the object of a specially evolved public affection that all psychologically normal humans have inherited from a long line of primates. 6

In Callicott's view, the biotic community has not only moral considerability but primacy; he writes, " not only are other sentient creatures members of the biotic community and subordinate to its integrity, beauty, and stability; so are we. ... human beings are equally subject to the same subordination of individual welfare and rights in respect to the good of the community as a whole."7 Callicott claims, however, that this subordination does not lead to what Regan calls "environmental fascism," devaluing humans in the name of environmental welfare. Callicott maintains that such fascism cannot occur because humans are stilll bound to respect individual human rights: "prior moral sensibilities and obligations attendant upon and correlative to prior strata of social involvement remain operative and preemptive."8

Although Callicout's and Leopold's land/environmental ethic rests on "the ecological concept of a biotic community," Callicott goes to some length to defend the intrinsic value of nonhuman species. At least part of his motivation is the widespread species extinctions occurring all over the planet. ${ }^{10}$

Providing for the intrinsic value of natural entities and nature as a whole, however, is problematic because this value apparently must be grounded in some property of the entity. Yet anyone could reasonably deny that a particular natural or metaphysical property, e.g., "richness," is truly good. To counter this difficulty, Callicott argues in Chapter Nine that "good and evil, like beauty and ugliness, rest in the final analysis upon feelings or sentiments which are, as it were, projected onto objects, persons, or actions and affectively 'color' them." ${ }^{\text {"11 }}$ In so arguing, Callic ott realizes that "intrinsic or inherent value in nature in the strict, objective sense of the terms must by definition be abandoned if one assumes a Humean subjectivist axiology." Nevertheless, he says, this subjectivist axiology allows natural beings to "be valued for themselves." 12 It also escapes relativism, according to Callicott, because sociobiology has achieved a "consensus of feeling" through the "biologization of ethics." Human ethical feelings, he claims, "have been standardized by natural selection."13 Moreover, he says, "since nature is the self fully extended and diffused, and the self, complementarily, is nature concentrated and focused...nature is intrinsically valuable to the extent that the self is intrinsically valuable." 14

Having explained various aspects of his environmental ethic, Callicott argues in Chapters Ten and Eleven that American Indian cultures provided their members with a land "wisdom" and an environmental ethical ideal that could help guide us out of our environmental malaise. In the next two chapters of his volume, Callicott argues, respectively, that genuine ecological education is the main way to reorient persons toward a land/environmental ethic, and that land aesthetics can contribute to the effort because it "calls attention to the psychic-spiritual rewards of maintaining the biological integrity and diversity of the rural landscape." 15

\section{Callicott's Ethical Insights}

Apart from whether one agrces with all aspects of Callicott's subjectivist environmental ethics, he has brought a number of insights to the study of how and why we value nature. I shall mention only four of these insights. First, in Chapter Two, Callicott points out that one of the difficulties with the animal-rights position is that often its proponents do not distinguish humandomestic communities (that include nonhuman animals) from natural or wild biotic communities. Instead, he argues, they say that being a subject of a life (in some sense) is sufficient for being a rights-holder. ${ }^{16}$ Apart from whether most animal liberationists fall victim to this error, ${ }^{17}$ Callicott's insight is a correct one. This is that the community concept is essential to the notion of moral obligation, and that different kinds of communities undergird different moral obligations. The insight 
is important, not only because much of contemporary ethics is erroneously individualistic/atomistic but also because significant philosophical discussions turn on the necessity of a shared moral community as the basis of duties to community members. Indeed, many of the arguments about rights to future generations focus on whether present and future persons can share the same kind of moral community (have the same conception of the good) as we do. Hence Callicott's point is not only helpful to his own argument but also central to moral philosophy in general.

Another Callicott insight, admittedly one noted by other thinkers as well, is that, throughout history we have gradually extended the boundaries of our moral community (Chapter Five). We have expanded our ethical sensitivities from white males to include blacks, women, children, the insane, persons spatially and temporally removed from us, all living beings, and even the natural environment. In emphasizing this important truth of descriptive ethics, Callicott challenges us both to broaden our own sensitivities and to rethink classical ethical theory.

Likewise, in a significant departure from traditional ethical theory, Callicott insightfully follows Hume and Darwin in arguing that altruism is as fundamental in human nature as egoism, and that there are inborn natural sentiments that have society as their natural object. ${ }^{18}$ Given the postulated egoism of the two main schools of modern moral philosophy (the deontological and the utilitarian), as Goodpaster recognizes, Callicott's taking the "higher road" of altruism is nothing short of refreshing and prophetic. The rational grounds for his doing so are compelling, because most arguments that all actions are done for self-serving reasons presuppose a tautological definition of "self serving" and are hence nonfalsifiable, nonempirical, and highly ideological. The psychological and political grounds for endorsing Callicott's founding moral philosophy on altruism are that positing such a foundation, even if it cannot be proved, is the only possible way of hoping to avoid narcissism. Otherwise, egoism will be a self-fulfilling prophecy for us all.

Finally, although I do not believe that "naturally selected" feelings justify particular ethical stances (see the arguments of the next section), Callicott is insightful when he argues that many moral values originate in the feelings. This insight locates the psychological beginnings (if not the justification) or morality in the correct place. Indeed without feelings like compassion, it is questionable whether a principled and rational morality is ever able to develop. Callicott's emphasis on feelings as the originators of morality is important, in part, because it forces those of us interested in moral education to emphasize the development of the whole person, not just to nurture her ability to engage in rational analysis. His insight is also significant because it enables environmentalists to begin environmental education at the level of feeling, at the level of experiences in nature, that Holmes Rolston recognized as crucial. ${ }^{19}$ Both these benefits would have been lost, had Callicott taken a more traditional, rationalistic approach to the origins of moral development.

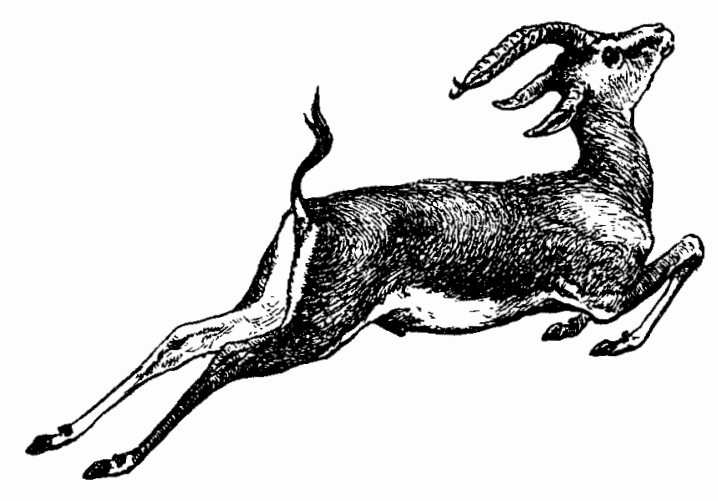

\section{Problems with Biological and Ethical Holism}

With so much to praise in Callicoth, especially his insistence on the importance of altruism and expanding our moral communities, are there areas in which his views are arguably false? The answer to this question, for me, is "yes," and the grounds for this response are, in part, biological. These are that (1) there is no biologically coherent notion of "community" mobust enough to ground either contemporary scientific theory in community ecology or environmental ethics; (2) contrary to Callicott's suggestion in Chapter Two, it is not possible to safeguard the interests of biological communities; and (3) in relying on natural-selection mechanisms to deliver it from relativism, Callicott's evolutionary ethics has lost its normative dimension. Let's examine these three points in order.

Following Leopold, Callicott argues that all creatures are subordinate to the integrity, beauty, and stability of the biotic community (see note 7). This imperative is problematic from a biological point of view because 
there is a clear notion neither of balance, integrity, or stability, nor of community. There is, for example, no clear sense in which one can claim that natural ecosystems proceed toward homeostasis, stability, or some balance. ${ }^{20}$ Likewise there is noconsensus among ecologists on the ecosystemic view of balance or stability, ${ }^{21}$ and almost no support for the diversitystability view held by MacArthur, Hutchinson, and Commoner. ${ }^{22}$ The reasons for the disfavor attributed to the view of MacArthur, et al are both empirical and theoretical. Salt marshes and the rocky intertidal are two of the many counterexamples to the diversitystability view, ${ }^{23}$ and empirically based counterexamples have multiplied over the last two decades. May, Levins, Connell, and others have seriously challenged the diversity-stability hypothesis on both mathematical and field-based grounds. ${ }^{24}$ Even though some laypersons and policymakers appeal to the hypothesis, ${ }^{25}$ most ecologists have either repudiated it or cast strong doubt on it. ${ }^{26}$

Doubts about balance and stability have arisen, in part, because ecologists cannot say what it would be, in a non-question-begging way, to hinder some balance, stability, or integrity. This is because communities and ecosystems regularly change and regularly eliminate species. Nature doesn't merely extirpate species or cause them to move elsewhere because their niches are gone. And if not, then there are no clear ecological grounds for defining and preserving some balance or stability. Hence it is not clear that Leopold's and Callicott's appeal to ecology can help environmental ethics in any precise, scientific way. ${ }^{27}$

It will not do to say that what happens naturally is good, whereas what happens through human intervention is bad; this would be to solve the problem of defining "balance" or "stability" in a purely stipulative or ad hoc way. Nor can the criterion be merely that it is wrong for humans to do quickly (e.g., cause lake eutrophication) what nature does more slowly. One would need an argument (given neither by Callicott nor Leopold) that accelerating ecosystemic changes is bad, even if the changes themselves are natural.

Another conceptual problem besetting environmental appeals to ecological balance, wholeness, or integrity is that ecologists must take into account thousands of different communities, species, and individuals, all relative to the health or balance of an ecosystem or the biosphere. It is unclear both how to define the health of a system (as opposed to an individual), since system health is relative to some specific goal, and how to define the system at issue. The ecological problem of defining the system at issue is analogous to the economic problem of defining a theory of social choice and choosing some "whole" that aggregates or represents numerous individual choices.

Defining an ecological "whole" to which Callicott and Leopold can refer is especially problematic, both because the biologists (e.g., Clements, Elton, Forbes) cited by Callicott to explicate his views are no longer accepted by contemporary scientists as being correct, and because the contemporary variant of Clements' position, the GAIA hypothesis, has been rejected by most ecologists as unproved metaphor or mere speculation. They admit the scientific facts of interconnectedness and coevolution on a small scale, but they point out that ecosystems and communities do not persist through time. Hence there is no clear referent for the alleged "dynamic stability" of an ecosystem or community. ${ }^{28}$

Moreover, it is not clear which (of many) alleged ecological communities it is whose balance or stability ought to be sought. One could seek to stabilize (whatever that means) the ecosystem, ${ }^{29}$ or the association, ${ }^{30}$ or the trophic level, for example. Or, if one is a holist, then why should not the collection of communities and ecosystems be optimized, namely, the biosphere? Optimizing the well-being of a particular community typically leads neither to the optimization of another community, nor to that of the biosphere, nor to that of a particular association. If not, than Callicott has no scientific basis for choosing a given "whole" as the unit that is to be optimized. ${ }^{31}$ One can make a value judgment to optimize the well-being of a particular community or the biosphere, or some ecosystem, but this is just that, a value judgment. Such a judgment is not part of ecological science.

Admittedly, once one makes a value judgment about which particular whole one wants to stabilize or balance, it is obvious that particular ecological conclusions are valid within certain spatial and temporal scales. Nevertheless a given ecological conclusion regarding balance or integrity, for example, typically holds for some "wholes," e.g., communities, but not for others. Ecologists cannot optimize the welfare of all the different wholes (each having a different spatial and temporal scale) at the same time. Because they cannot, there is no general level at which ecological problem solving takes place. Hence there is no general 
temporal or spatial scale within which a stable "whole" is exhibited.

Because there is no universal ecological theory that can be appealed to in defining the "whole" about which Leopold and Callicott speak, ecologists are forced to work on a case-by-case basis. They recognize that there is no universal level, across all communities, at which some balanced or stable whole exists. In part this is because numerous alleged "wholes," e.g., populations, exhibit density vagueness rather than density dependence, while other wholes do not. ${ }^{32}$ It is also because many ecosystemic or holistic explanations are neither falsifiable nor even testable. This is why at least one scientist called ecosystems ecology "theological ecology." 33 There is neither a clear definition of what it is to be balanced or stable, nor a clear definition of the whole that is allegedly balanced or stable. This is ultimately because theorists do not agree on the underlying processes that structure communities and ecosystems. ${ }^{34}$

A second biological problem with Callicott's grounding environmental ethics on ecology occurs in Chapters Two and Three. There he argues in favor of duties to the biotic community and against according rights to individual members of the biotic community. $\mathrm{He}$ argues against the latter because he says that it is not possible to safeguard the rights of each individual; such a "safeguard" would stop all trophic processes beyond photosynthesis. ${ }^{35}$

The biological problem with Callicott's reasoning here is that nature does not respect communities either. There is strong biological evidence (e.g., fossilized pollens) of radical changes in community composition and structure throughout history. These changes in community composition and structure, in turn, suggest that there is no such thing as a stable or balanced community "type" existing through time. Rather the types only appear stable because our time frame of examination is relatively short. Even if climate and environment remained the same, communities could not be classified into balanced or stable "types" on the basis of climate. Both spatial and temporal fluctuations undercut any universal notion of a stable or balanced community. ${ }^{36}$ And if so, then the same argument that Callicott uses against Regan (in his Chapters Two and Three) can be used against him. Nature does not respect communities so, on Callicott's own terms (this is not an argument that I would make), how can he avoid a stipulative and question-begging argument that humans ought to respect communities?

A third problem with Callicott's using biology to undergird his environmental ethics is that he destroys the normative dimension of his ethics. This occurs because Callicott reasons, quite correctly, that in relying on a Humean notion of ethics, he is open to the charge of ethical relativism. He avoids this relativism by postulating that ethical uniformity/unanimity is achieved by means of natural selection. He says "human feelings... have been standardized by natural selection" (see note 13). The problem this creates, however, is that one cannot be morally bound to do something against natural selection or against his genetic make-up. And one cannot be praised for acting in accord with natural selection. Either a certain ethical tendency is selected for, or it is not. This means that behavioral uniformities that are explained through natural selection are descriptive, not normative. Hence Callicott has admittedly saved his ethics from relativism, but at the price of its "oughtness" or normative character.

A similar situation occurs when epistemologists attempt to explain rules or norms of knowing by means of natural selection; their "evolutionary epistemology," apart from its other problems, is naturalized, descriptive, and non-normative. It is no longer epistemology, but psychology. ${ }^{37}$ Like evolutionary epistemology, Callicott's evolutionary ethics runs into these same problems. Why does this follow? There are at least three difficulties with appealing to natural selection as a way of grounding evolutionary ethics. First, arriving at ethical beliefs/actions relies on cognitive and evaluative aims, on anticipating experience, solving problems, and so on. The evolution : ethics analogy therefore breaks down because, al though evolution does not operate according to ends or aims, ethics does. Moreover, evolution and natural selection ignore the contribution to reflective self-understanding of ourselves as agents of inquiry, while this reflective agency is at the core of ethical knowledge. ${ }^{38}$ Moreover, the natural selection explanation fails to explain how someone could make the first correct ethical guess or have the first ethical feeling; at best, natural selection could only explain later correct guesses or feelings. ${ }^{39}$

Evolution and ethics are also disanalogous in that, in ethics, we select theories/behavior on the basis of hypotheses about the facts and our evaluations of them. In evolution, however, each variation arises 
independently of the adaptive needs of the organism. The facts themselves, not our theories or evaluations of them, guide evolution. Hence evolution is blind to the adaptive needs of the organism, whereas ethics is blind to the facts, and can see only hypotheses about the facts. ${ }^{40}$

A third difficulty with Callicott's (or any) evolutionary ethics is that he uses it to move from biological theory to realistic ethics. But for this inference to be successful, we must know that the organism has an accurate representation of the environment. We don't know this. ${ }^{41}$ For all these reasons, Callicott's appeal to natural selection appears to create more philosophical problems than it solves.

\section{Conclusion}

If Callicott is unable to use natural selection and community ecology to "bail out" environmental ethics, then where do we go from here? Clearly Callicott deserves high praise for showing us much of what is wrong with traditional moral philosophy. Nevertheless, my own preferences are for a metaphysical account that posits intrinsic value in nature itself, an account that deviates only slightly from that of Paul Taylor (see note 17). Admittedly, however, there is neither time nor space to discuss such an account here. If my preferences eventually prove to be correct, then despite Callicott's poetic brilliance and his creative appeal to biology, we must follow a path somewhat different from his.

Perhaps ultimately we must rely more on metaphysics, and less on biological science, if we wish to build (or discover) an environmental ethics. Just as we leamed that there are no "technological fixes" that will give us easy answers to environmental problems, perhaps also there are no "scientific fixes" (like natural selection) that will give us easy answers to ethical problems. Callicott has helped us begin to ask the hard questions.

\section{Notes}

The biological part of this work was supported by NSF grant BBS-8619533. The opinions expressed are those of the author and not the National Science Foundation.

${ }^{1} \mathrm{~J}$. Baird Callicott, In Defense of the Land Ethic: Essays in Envirommental Philosophy (Albany: State University of New York Press, 1989); hereafter cited as Callicott, LE.
2 Callicott, LE, p. 37.

3 Callicott, LE, p. 43.

${ }^{4}$ Callicott, LE, pp. 51, 58.

5 Callicott, LE, pp. 82-83.

${ }^{6}$ Callicott, LE, p. 86.

7 Callicott, LE, pp. 92-93.

${ }^{8}$ Callicott, LE, p. 93.

${ }^{9}$ Callicott, LE, p. 126.

${ }^{10}$ Callicoth, LE, pp. 154-155.

11 Callicott. LE, p. 160.

12 Callicott, LE, p. 161.

13 Callicott, LE, p. 164.

${ }^{14}$ Callicott, LE, p. 174.

15 Callicott, LE, p. 201.

16 Callicott, LE, p. 47.

${ }^{17}$ See Paul Taylor, Respect for Nature (Princeton: Princeton University Press, 1986). Taylor clearly makes the distinction between natural and domestic communitics of animals.

18 Callicott, LE, pp. 84-85, 142-143.

19 See Holmes Rolston, Philosophy Gone Wild (Buffalo: Prometheus, 1986), esp. pp. 221-262.

20 P. Taylor, for example, urges us to "preserve ecological integrity" (Taylor, Respect, p. 299) but he never tells us what ecological integrity is.

21 Taylor, for example, denies that ecology can inform environmental ethics (Taylor, Respect, p. 8).

22 See Mark Sagoff, "Fact and Value in Environmental Science,"Environmental Ethics 7:2 (Summer 1985) : 107-110; hereafter cited as: Sagoff, Fact. See also Taylor, Respect,p. 8.

23 M. Sagoff, "Environmental Science and Environmental Law," (College Park, Maryland: Center for Philosophy and Public Policy, March, 1985), unpublished essay, p. 109; hereafter cited as: ES. 
${ }^{24}$ See works by May, Levins, and Connell cited in note 26; see also Sagoff, Fact, p. 109, and R. P. Mclntosh, The Background of Ecology: Concept and Theory (Cambridge: Cambridge University Press, 1985), pp. 187-188; hereafter cited as: Background.

${ }^{25}$ See, for example, U.S. Congress, Senate, Congressional Record, 93rd Congress, First Session, 119 (24 July 1973): 25668; B. Commoner, The Clasing Circle (New York: Knopf, 1971), p. 38; and N. Myers, A Wealth of Wild Species (Boulder: Westview Press, 1983).

${ }^{26}$ See Sagoff, Fact, p. 107. See Also R. T. Paine, "A Note on Trophic Complexity and Community Stability," American Naturalist 103 (1969): 91-93; R. Lewin, "Fragile Forests Implied by Pleistocene Data," Science 226 (1984): 36-37; R. M. May, Stability and Complexity in Model Ecosystems (Princeton: Princeton University Press, 1973); R. Levins, "The Qualitative Analysis of Partially Specified Systems," Annals of the New York Academy of Sciences 231 (1974): 123138; J. H. Connell, "Diversity in Tropical Rain Forests and Coral Reefs," Science 199 (1978): 1302-1310; Daniel Goodman, "The Theory of Diversity-Stability Relationships in Ecology," The Quarterly Review of Biology 50: 3 (September 1975): 237-266. See also M. E. Soule, "Conservation Biology and the 'Real World'," in Soule, CB, pp. 6-7, who argues that diversity-stability can be said to be a working hypothesis, even though it fails to have the empirical backing to satisfy experts and even though there are several categorical exceptions to it. Finally see R. P. McIntosh, Background, p. 142.

${ }^{27}$ See the previous note.

28 See Taylor, Respect, pp. 45-46, 225-226, 246, 259. 281-282.

${ }^{29}$ See R. MacArthur, "Fluctuations of Animal Populations, and a Measure of Community Stability," Ecology 36 (1955): 533-536 (hereafter cited as Fluctuations); Daniel Goodman, "The Theory of Diversity-Stability Relationships in Ecology," The Quarterly Review of Biology 50 (1975): 237-266; hereafter cited as: Theory. Note also that different camps of ecologists would probably claim that different units ought to be maximized.

${ }^{30}$ Ecologists who follow Clements are likely to make this claim. See Mclntosh, Background, pp. 44, 79, 107.

31 McIntosh, Background, pp. 228, 252-256. B. Norton, "Environmental Ethics and the Rights of Nonhumans," Environmental Ethics 4 (1982): 17-36, raises a similar point. See McIntosh, Background, for a discussion of community ecology (pp. 69-146, 263-267), population ecology (pp. 146193), and ecosystems ecology (pp. 193-242).
32 Many ecologists follow the Platonic, holistic paradigm of reifying and studying organic entities like ecosystems, while others follow the nominalistic and reductionistic paradigm of examing the individual or the species and refrain from creating higher-level holistic entities such as ecosystems. Neither side has won acceptance, but most of the predictive power is on the side of the reductionists, despite the fact that advances are possible through holistic approaches. McIntosh, Background, pp. $126 \mathrm{ff}$., 157 ff., 181-182 ff. and 252; see K. Shrader-Frechette, "Organismic Biology and Ecosystems Ecology," in Current Issues in Teleology, ed. by N. Rescher (Pittsburgh: University of Pittsburgh Center for the Philosophy of Science, 1986), pp. 77-92; hereafter cited as: Biology. For information on density dependence, see D. Strong, "Density Vagueness: Abiding the Variance in the Demography of Real Populations," in Community Ecology, ed. by J. Diamond and T. Case (New York: Harper and Row, 1986).

${ }^{33}$ McIntosh, Background, p. 193. Ecosystems ecology is allegedly empirical, but the ecosystemic entity about which it centers is not defined clearly. Ecosystems can be of many kinds and many sizes. This being so, it is not precisely clear that particular claims about ecosystems are falsifiable.

34 What pattern of excellence is it which an ecosystem maximizes? Ecologists cannot answer the question. Theorists such as Diamond and Gilpin, following MacArthur, claim that interspecific competition is a major factor in patterning natural processes of ecosystems. Other ecologists, such as Simberloff and Strong, argue that the Diamond and Gilpin theories are untestable. Strong and Simberloff have created numerous null models which (they claim) indicate that observed patterns of species occurrence do not depart from what one would expect if associations were purely random. (See M. Cody and J. Diamond (eds.), Ecology and the Evolution of Communities (Cambridge: Harvard University Press, 1975); D. Strong et al. (eds.), Ecological Communities (Princeton: Princeton University Press, 1984), especially M. Gilpin and J. Diamond, "Are Species Co-occurrences...?," pp. 298-315. See also D. S. Simberloff, "Competition Theory, Hypothesis Testing, and Other Community Ecological Buzzwords," American Naturalist 122 (1983): 626-635.

Moreover, the evolutionary foundations of ecology seem to suggest that many, many different happenings in ecosystems might be stable, integral, and balanced. It is not clear that there is a moral reason, short of human welfare, to prefer one temporal arrangement or stability over another. In other words, the evolutionary foundations of ecology seem to undercut a precise definition of stability, at least a definition formulated in purely non-anthropocentric terms. Admittedly it is easy to formulate some definition of stability in terms of human needs and interests, but this is precisely what proponents of holism typically want to avoid doing; they want a non-anthropocentric environmental ethics. 
But if there is no accepted natural process followed by ecosystems that are "maximizing excellence," then how did competition become so entrenched in "explaining" ecosystemic processes? One scientist claims that competition has survived as an hypothesis merely because it fits in with our notions of homeostasis and the balance of nature. ( $R$. Levin "Santa Rosalia Was a Goat," Science 221 [12 August 1983]: 636-639.) If this is so, and I think that it is, then ecology is in the midst of a revolution, Kuhnian or not, to overthrow entrenched and untestable competitionism. This is a significant revolution because competitionism allegedly provides the major explanation of the processes underlying natural systems; it allegedly explains the "machine" which drives the ecosystem to maximize something or other called "excellence."

${ }^{35}$ Callicott, LE, pp. 43, 51.

${ }^{36}$ See the Strong reference in note 32 . See also $M$. Davis, "Climatic Instability, Time Lags, and Community Disequilibrium," and R. Graham, "Response of Mammalian Communities to Environmental Changes During the Late Quaternary," in Community Ecology, eds. J. Diamond and T. Case (New York: Harper and Row, 1986), pp. 269-284 and 300-313.

37 Our arriving at a particular ethical stance, on a sociobiological account, is not determined by our current experience, or whether we think the stance is morally justifiable, or whether or not it is a correction of previous erroneous stances. This is because neither in the production of evolutionary variations nor in the elimination of disadvantageous variations is there any reference to an end of producing "fit" species. Adaptive needs have little to do with the promotion of moral goodness. Hence there is little reason to believe that millions of years of evolution should "guarantee" anything, especially moral value. This is because, within evolutionary theory, the probability of variation occurring is independent of the need for a change to produce a better fit between organisms and the environment. Within the knowledge process, however, the probability of a varied hypothesis occurring is not independent of the need for a change to produce a better fit between a moral stance and the facts. See W. Bartley, "Philosophy of Biology Versus Philosophy of Physics," in G. Radnitzky and W. Bartley, eds., Evolutionary Epistemology, Rationality, and the Sociology of Knowledge (La Salle, Illinois: Open Court, 1987), pp. 2425 , who makes similar points regarding evolutionary epistemology. See also A. O'Hear, “Has the Theory of Evolution Any Relevance to Philosophy?" Ratio XXIX (1 June 1987): 19-23; hereafter cited as: O'Hear. Finally see C. Hookway, "Naturalism, Fallibilism, and Evolutionary Epistemology," in C. Hookway, ed., Minds, Machines, and Evolution (Cambridge: Cambridge University Press, 1984), pp. 1-16; hereafter cited as: Hookway.
${ }^{38}$ Hookway, pp. 13-15, makes similar points. See also O'Hear, pp. 27-29.

39 Even if we need blind variation to acquire new knowledge, moral progress could not occur if the variation were totally blind. Moreover, the sociobiologist is unable to explain the probability of the first correct ethical stance. (P. Skagestad, "Taking Evolution Seriously: Critical Comments on D. T. Campbell's Evolutionary Epistemology," in The Monist 61, No. 4 (October 1978): 615, makes a similar point; hereafter cited as: Skagestad.) And if not, then he has not explained ethics as we know it.

40 The opportunism of biological evolution has no counterpart in the evolution of ethics because evolution is characterized by blindness before the fact and wisdom after the fact, whereas ethics is not wholly wise either before or after the fact. Once we grant that ethical stances are selected in part on the ground of hypotheses about the facts, rather than on the ground of the facts themselves, then the blindness of hypothesis formation is carried over to the stage of hypothesis selection. Hence evolution is not blind in the way that moral evolution is blind. Why should one say these two cases are similar, and that they both involve natural selection? They are wildly disanalogous. Skagestad, p. 617, makes a similar point.

${ }^{41}$ O'Hear, p. 25, makes a similar point.

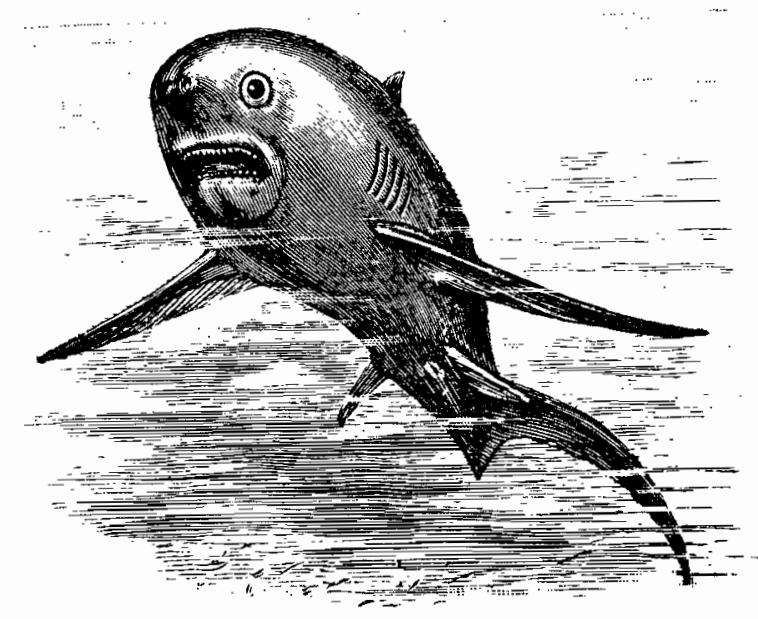

